\title{
Inequalities in breast cancer incidence and stage distribution between urban and rural female population in Świętokrzyskie Province, Poland
}

\author{
Agnieszka Paszko, ${ }^{1, A-F}{ }^{\oplus}$, Michalina Krzyżak ${ }^{1, A, C-D \oplus}$, Angelika Edyta Charkiewicz ${ }^{2, D \oplus,}$, \\ Dominika Ziembicka ${ }^{2, B \oplus}$, Małgorzata Żendzian-Piotrowska ${ }^{1, E \oplus}{ }^{\infty}$ Andrzej Stanisław Szpak ${ }^{3, E-F} \oplus$, \\ Magdalena Florek-Łuszczki ${ }^{4, \mathrm{E}-\mathrm{F}}{ }^{\oplus}$, Dominik Maślach ${ }^{2, \mathrm{C}, \mathrm{F} \oplus}$ \\ ${ }^{1}$ Department of Hygiene, Epidemiology and Ergonomics, Medical University, Bialystok, Poland \\ ${ }^{2}$ Department of Public Health, Medical University, Bialystok, Poland \\ ${ }^{3}$ Department of Epidemiology and Biostatistics, Witold Chodźko Institute of Rural Health, Lublin, Poland \\ ${ }^{4}$ Department of Gerontology, Witold Chodźko Institute of Rural Health, Lublin, Poland \\ A - Research concept and design, B - Collection and/or assembly of data, C - Data analysis and interpretation, \\ $D$ - Writing the article, E - Critical revision of the article, F - Final approval of article
}

\begin{abstract}
Paszko A, Krzyżak M, Charkiewicz AE, Ziembicka D, Żendzian-Piotrowska M, Szpak AS, Florek-Łuszczki M, Maślach D. Inequalities in breast cancer incidence and stage distribution between urban and rural female population in Świętokrzyskie Province, Poland. Ann Agric Environ Med. 2019; 26(1): 159-164. doi: 10.26444/aaem/102380
\end{abstract}

\section{Abstract}

Introduction and objective. One of the main factors determining the burden of breast cancer is the effectiveness of measures taken to combat this cancer including urban-rural differences. The aim of the study was to analyse the differences in breast cancer incidence and disease stage distribution among urban and rural women in the Świętokrzyskie Province as a part of a strategy for breast cancer control.

Materials and method. The study of disease stage distribution included 483 female residents of Świętokrzyskie Province who were diagnosed in 2013 with invasive breast cancer, and reported to Świętokrzyskie Office for Cancer Registration. Urban-rural differences in breast cancer incidence in 2002-2013 were presented using Range Ratio (RR). Changes in incidence trends in urban and rural areas were analysed using joinpoint models. Annual Percentage Change (APC) of the rates was calculated for each time trend.

Results. Breast cancer incidence rate in the urban female population was higher than in rural women with RR, amounting to 1.43. However, the analysis of trends showed that the pace and direction of change were developing negatively among inhabitants of rural areas. In 2002-2013, in rural women, the age-standardized rate (ASR) values increased by $2.8 \%$ per year $(p<0.05)$. The course of ASR trends showed statistically significant urban-rural differences $(p=0.004)$. Analysis of urban-rural differences in disease stage distribution revealed a non-significantly higher proportion of cases with localised stage in urban than in rural areas, amounting to $51.0 \%$ and $43.9 \%$, respectively.

Conclusions. Existing health inequalities indicate the need to intensify activities in rural areas and should be the starting point for making key decisions in combating breast cancer.

\section{Key words}

breast cancer, incidence, inequalities in health, urban and rural population, stage distribution

\section{INTRODUCTION}

Breast cancer is the most common cancer among women worldwide. In 2012, 1,671,149 breast cancer cases were reported, which constituted $25 \%$ of all malignant tumours in women. The age-standardized rate (ASR) was $47.8 / 10^{5}$. In 2012, there were 6.3 million women living who had been diagnosed with breast cancer in the previous 5 years. The diversification of global breast cancer burden results from differences in exposure to risk factors and unequal accessibility to early detection programmes [1].

An unhealthy lifestyle contributes to the increasing incidence of cancer, as well as urbanization-related

Address for correspondence: Dominik Maślach Department of Public Health, Medical University of Bialystok, Poland

e-mail: dominikm@umb.edu.pl

Received: 12.10.2018; accepted: 27.12.2018; first published: 16.01.2019 changes in reproduction patterns, economic development, environmental and socio-economic factors prevailing in a given country [2].

Efforts are being made in Poland to combat breast cancer. The implementation of the first in Poland Population Breast Cancer Early Detection Programme, organised on a national scale in 2006 as an integral element of the National Programme for Combating Cancer Diseases, was an important moment in the creation of cancer control strategy. Reducing health inequalities, also between urban and rural areas, is an important strategic goal of the National Health Programme for 2016-2020 [3].

One of the main factors determining the burden of breast cancer is the effectiveness of measures taken to combat this cancer, including urban-rural differences.

Reliable information on the burden of breast cancer is the basis for the development of strategies for cancer control 
programmes. However, in the context of the evaluation of breast cancer control strategy, knowledge about the epidemiological situation based on the risk assessment of the breast cancer should be supplemented with more detailed information on the diagnosis and treatment of the cancer.

The aim of the study was to analyse the differences in breast cancer incidence and disease stage distribution among urban and rural women in the Swiętokrzyskie Province as a part of the strategy for breast cancer control.

\section{MATERIALS AND METHOD}

The study material included information from the Cancer Registry Card MZ/N.1a. The analysis of breast cancer incidence in the Świętokrzyskie Province in 2002-2013 was based on data collected from the Świętokrzyskie Office for Cancer Registration in Kielce. Population numbers in the Province in the analysed years were obtained from the database of the Central Statistical Office in Poland, taking into account the place of residence (urban/rural). Crude rates (CR), age-standardized rates (ASR) and age-specific incidence rates were calculated per 100,000 people. The technique of direct standardization was applied for ageadjustment according to the World Health Organization standard population $[4,5]$. Age-specific incidence rates for 5-year age groups were also calculated and grouped as follows: $<50,50-69, \geq 70$-years-old.

Breast cancer cases were coded according to International Classification of Diseases for Oncology (ICD-O-3) [6]. Place of residence (urban/rural) was determined on the basis of the patient's address obtained from the National Official Register of Territorial Division of the Country (TERYT). Urban population was defined if urban official municipal rights were granted.

Information on disease stage distribution was collected based on the Protocol of EUROCARE (European Cancer Registry Based Study on Survival and Care of Cancer Patients) High Resolution Study. The study included 483 female residents of the Świętokrzyskie Province, diagnosed in 2013 with invasive breast cancer. Breast cancer diagnosis was microscopically confirmed in $100.0 \%$ of the cases. There were no cases notified by death certificate only (DCO). Chi square tests were used to examine differences between urban and rural disease stage distribution, and the $p$ value of $\leq 0.05$ was considered statistically significant.

In order to evaluate disease stage distribution, simplified classification recommended by ENCR (European Network of Cancer Registries) for population registries (localised, regional, advanced) was applied [7].

Changes in breast cancer incidence trends overall and in urban and rural areas were analysed using joinpoint models. In this analysis, which is the extension of the linear regression, time trend, is expressed by the lines connected together at the joinpoints in which it changes direction statistically significantly $(\mathrm{p}<0.05)$. On the basis of the linear regression model, in which natural logarithm of incidence rate was a dependent variable and a calendar year was an independent variable, an Annual Percentage Change (APC) of rates was calculated for each time trend with $95 \%$ confidence intervals (CI). The p value of $<0.05$ was considered statistically significant. The trend direction of incidence rates was compared between urban and rural areas using the joinpoint test for parallelism. The APC values were calculated and the time trends were analysed using Joinpoint Regression Program 4.2.0.2, recommended by U.S. National Cancer Institute for this type of analyses [8].

Incidence rates were compared between the urban and rural areas by means of Range Ratio (RR) showing the ratio of rate values in the urban and rural areas. For this inequality measure standard errors (SE) and 95\% confidence intervals were assessed at each time point. To compare crude, agestandardized and age-specific incidence and mortality rates between urban and rural areas, Health Disparities Calculator (Version 1.2.4) was used, developed by the U.S. National Cancer Institute to evaluate and monitor health inequalities $[9,10]$.

\section{RESULTS}

Incidence and trends in breast cancer incidence. The average annual incidence rate in the Świętokrzyskie Province in $2002-2013$ was $42.1 / 10^{5}$ and $67.9 / 10^{5}$ (crude), with the highest value in the age group recommended for screening in Poland, that is 50-69 years - 150.1/10 .

Average annual incidence rates in 2002-2013 were markedly higher in urban than in rural areas, and amounted, respectively, to: urban $-49.4 / 10^{5}$ (crude $85.5 / 10^{5}$ ), rural $34.9 / 10^{5}$ (crude 52.7/10 $)$. Age-specific average annual incidence rates were higher in urban than in rural women in every analysed age group (Tab. 1).

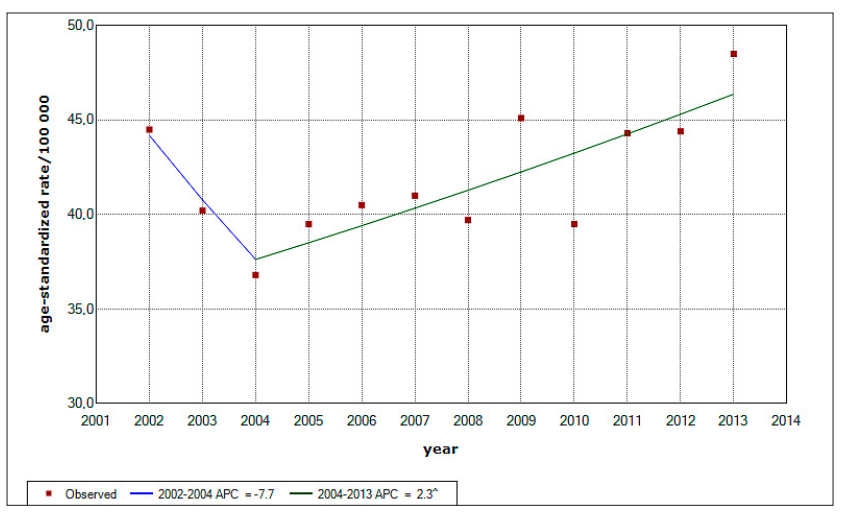

Figure 1. Trends in breast cancer incidence in women in the Świętokrzyskie Province in 2002-2013

In the Swiętokrzyskie Province after 2004, the value of ASR increased at a rate of $2.3 \%$ per annum (Fig. 1, Tab. 2).

Table 3 presents trends in breast cancer incidence in urban and rural women. In 2002-2013, in rural women the crude rate incidence values increased by $2.8 \%$ per year $(\mathrm{p}<0.05)$, and the standardized incidence rate values also by $2.8 \%$ per year $(p<0.05)$. The course of ASR trends showed statistically significant urban-rural differences $(\mathrm{p}=0.004)$.

Between 2002-2013, in rural women aged 15-49 years, the value of the incidence rate increased by $2.6 \%$ per year $(\mathrm{p}<0.05)$. The course of trends showed statistically significant urban-rural differences $(\mathrm{p}=0.01)$.

In urban women aged 50-69 years, the incidence rate values decreased slightly until 2011at the rate of $0.1 \%$ per year; thereafter, a statistically significant increase in the incidence at a level $23.8 \%$ per year was observed ( $\mathrm{p}<0.05)$. In 2002-2013, in rural areas the direction of the trend was 
Table 1. Breast cancer incidence in women in Świętokrzyskie Province, 2002-2013

\begin{tabular}{lccc}
\hline Incidence rate* & Overall & Urban & Rural \\
\hline CR & 67.9 & 85.5 & 52.7 \\
\hline ASR & 42.1 & 49.4 & 34.9 \\
\hline Age group & & & \\
\hline$<50$ & 28.9 & 33.4 & 24.8 \\
\hline $50-69$ & 150.1 & 180.6 & 121.6 \\
\hline$\geq 70$ & 127.7 & 174.1 & 96.6 \\
\hline
\end{tabular}

* average annual value per $10^{5}$ in the years $2002-2013$

Table 2. Trends in breast cancer incidence in women in Świętokrzyskie Province, 2002-2013

\begin{tabular}{lcccc}
\hline & Years & APC & $95 \% \mathrm{Cl}$ & $\mathrm{p}$ \\
\hline CR & $2002-2004$ & -7.2 & $-22.2 ; 10.8$ & 0.354 \\
& $2004-2013$ & $3.2^{\wedge}$ & $1.5 ; 4.9$ & 0.003 \\
\hline \multirow{2}{*}{ ASR } & $2002-2004$ & -7.7 & $-22.0 ; 9.1$ & 0.295 \\
\hline Age group & $2004-2013$ & $2.3^{\wedge}$ & $0.8 ; 3.9$ & 0.009 \\
\hline $15-49$ & $2002-2013$ & -0.4 & $-2.3 ; 1.6$ & 0.689 \\
\hline $50-69$ & $2002-2013$ & $2.2^{\wedge}$ & $1.0 ; 3.4$ & 0.002 \\
\hline$\geq 70$ & $2002-2013$ & -1.2 & $-4.1 ; 1.8$ & 0.403 \\
\hline
\end{tabular}

${ }^{\wedge} \mathrm{APC}$ is significantly different from zero at $\mathrm{p}<0.05$

Table 3. Trends in breast cancer incidence in urban and rural women in Świętokrzyskie Province, 2002-2013

\begin{tabular}{lccccccc}
\hline & \multicolumn{5}{c}{ Urban } & \multicolumn{3}{c}{ Rural } & p a \\
\cline { 2 - 7 } & Years & APC & $95 \% \mathrm{Cl}$ & Years & APC & $95 \% \mathrm{Cl}$ & \\
\hline CR & $2002-2013$ & 1.5 & $-0.4 ; 3.4$ & $2002-2013$ & $2.8^{\wedge}$ & $1.5 ; 4.1$ & 0.257 \\
\hline ASR & $2002-2013$ & -0.1 & -1.8 .1 .5 & $2002-2013$ & $2.8^{\wedge}$ & $1.3 ; 4.3$ & 0.004 \\
\hline Age group & & & & & & \\
\hline $15-49$ & $2002-2013$ & -2.4 & $-4.9 ; 0.1$ & $2002-2013$ & $2.6^{\wedge}$ & $0.2 ; 5.0$ & 0.010 \\
\hline $50-69$ & $2002-2011$ & -0.1 & $-1.5 ; 1.3$ & $2002-2013$ & $3.4^{\wedge}$ & $1.8 ; 5.1$ & 0.039 \\
\hline $2011-2013$ & $23.8^{\wedge}$ & $6.1 ; 44.5$ & & & & \\
\hline$\geq 70$ & $2002-2013$ & -2.0 & $-2.0 ;-6.7$ & $2002-2013$ & -1.1 & $-3.6 ; 1.4$ & 0.767 \\
\hline $\begin{array}{l}\text { a p value in the test for differences in trends between urban and rural areas } \\
\text { ^APC is significantly different from zero at } p<0.05\end{array}$ & & & &
\end{tabular}

upward $(\mathrm{APC}=3.4 \% ; \mathrm{p}<0.05)$. The course of trends showed statistically significant urban-rural differences $(p=0.039)$.

Urban-rural inequalities in breast cancer incidence. In 2002-2013, breast cancer incidence in the Świętokrzyskie Province was higher in urban women than in rural women. RR was 1.63 (CR) and 1.43 (ASR), on average.

In 2013, compared to 2002, inequalities reduction in urban-rural breast cancer incidence was observed according to the RR by $4.3 \%$ based on crude rate values, and by $20.3 \%$ based on age-adjusted values (Tab. 4).

In all age groups there were significant urban-rural differences in the level of breast cancer incidence. The largest inequalities in incidence between urban and rural areas occurred in the age group of 70 years and more, which is reflected by $\mathrm{RR}$ and amounted to 1.82 . In this age group, the incidence, on average, was $82 \%$ higher in urban than in rural areas. The smallest urban-rural disparities in breast cancer incidence were observed in the youngest age group (15-49
Table 4. RR of crude and age-adjusted breast cancer incidence rates in women in Świętokrzyskie Province, 2002-2013

\begin{tabular}{lcccc}
\hline & RR & Odds $^{\mathrm{b}}(\%)$ & $\mathrm{SE}$ & $95 \% \mathrm{Cl}$ \\
\hline $\mathbf{C R}$ & & & & \\
\hline 2002 & 1.93 & 0.0 & 0.2 & $1.6 ; 2.3$ \\
\hline 2013 & 1.85 & -4.3 & 0.2 & $1.6 ; 2.2$ \\
\hline $2002-2013^{*}$ & 1.63 & - & - & - \\
\hline ASR & & & & \\
\hline 2002 & 1.76 & 0.0 & 0.2 & $1.4 ; 2.1$ \\
\hline 2013 & 1.40 & -20.3 & 0.1 & $1.2 ; 1.7$ \\
\hline $2002-2013^{*}$ & 1.43 & - & - & - \\
\hline
\end{tabular}

* average annual value in the years 2002-2013

bodds in RR value between 2002 and 2013

Table 5. RR of age-specific breast cancer incidence rates in women in Świętokrzyskie Province, 2002-2013

\begin{tabular}{lccc}
\hline Year & $15-49$ & $50-69$ & $\geq 70$ \\
\hline 2002 & 1.76 & 1.62 & 2.87 \\
\hline 2013 & 1.26 & 1.84 & 2.53 \\
\hline $2002-2013^{*}$ & 1.40 & 1.50 & 1.82
\end{tabular}

* average annual value in the years 2002-2013

Table 6. RR of age-specific breast cancer incidence rates in women aged 15-49, 50-69 and $\geq 70$ years in Świętokrzyskie Province, 2002-2013

\begin{tabular}{lcccc}
\hline & $\mathrm{RR}$ & Odds $^{\mathrm{b}}(\%)$ & $\mathrm{SE}$ & $95 \% \mathrm{Cl}$ \\
\hline $\mathbf{1 5 - 4 9}$ & & & & \\
\hline 2002 & 1.76 & - & 0.3 & $1.2 ; 2.6$ \\
\hline 2013 & 1.26 & -28.5 & 0.3 & $0.8 ; 1.9$ \\
\hline $\mathbf{5 0 - 6 9}$ & & & & \\
\hline 2002 & 1.62 & - & 0.2 & $1.2 ; 2.2$ \\
\hline 2013 & 1.84 & 13.7 & 0.2 & $1.5 ; 2.3$ \\
\hline $\mathbf{7 0}$ & & & & \\
\hline 2002 & 2.87 & - & 0.5 & $2.1 ; 4.0$ \\
\hline 2013 & 2.53 & -11.7 & 0.5 & $1.7 ; 3.7$ \\
\hline
\end{tabular}

bodds in RR value between 2002 and 2013

years), where the incidence, on average, was $40 \%$ higher in the urban than in the rural female population. In women aged $50-69$, the incidence, on average, was $50 \%$ higher in urban residents (Tab. 5).

In 2013, compared to 2002, in the Świętokrzyskie Province in women aged $15-49$ and in women aged 70 years and older, urban-rural incidence inequalities were reduced according to the RR index, while in the group aged 50-69 an increase was observed (Tab. 6).

Breast cancer stage distribution. In 2013, there were 483 new invasive breast cancer cases in the Swiętokrzyskie Province registered in the Świętokrzyskie Office for Cancer Registration in Kielce. The majority, i.e. 296 (61.3\%) breast cancer patients, lived in urban, and the rest - 187 (38.7\%), in rural areas. Most $-60.2 \%$ of the women, were in the age group 50-69-years-old. Data completeness on disease stage reached $94.4 \%$. Breast cancer stage distribution was as follows: localised $48.2 \%$, regional $38.1 \%$ and advanced 8.1\% (Tab. 7).

Patients in urban and rural areas were different in terms of age group $(\mathrm{p}=0.0498)$. Women in the $50-69$ age group 
Table 7. Characteristics of breast cancer patients in Swiętokrzyskie Province, 2013

\begin{tabular}{lcccccc}
\hline & \multicolumn{2}{c}{ Urban } & \multicolumn{2}{c}{ Rural } & \multicolumn{2}{c}{ All cases } \\
\cline { 2 - 8 } & $\begin{array}{c}\text { No. of } \\
\text { women }\end{array}$ & $\%$ & $\begin{array}{c}\text { No. of } \\
\text { women }\end{array}$ & $\%$ & $\begin{array}{c}\text { No. of } \\
\text { women }\end{array}$ & $\%$ \\
\hline Age group & & & & & & \\
\hline $15-49$ & 48 & 16.2 & 47 & 25.1 & 95 & 19.7 \\
\hline $50-69$ & 184 & 62.2 & 107 & 57.2 & 291 & 60.2 \\
\hline$\geq 70$ & 64 & 21.6 & 33 & 17.6 & 97 & 20.1 \\
\hline Stage & 151 & 51.0 & 82 & 43.9 & 233 & 48.2 \\
\hline localised & 108 & 36.5 & 76 & 40.6 & 184 & 38.1 \\
\hline regional & 22 & 7.4 & 17 & 9.1 & 39 & 8.1 \\
\hline advanced & 15 & 5.1 & 12 & 6.4 & 27 & 5.6 \\
\hline not available & 296 & 100.0 & 187 & 100.0 & 483 & 100.0 \\
\hline All cases & & & & & &
\end{tabular}

constituted the majority in both populations; the proportion was $62.2 \%$ in urban areas and $57.2 \%$ in rural areas. The percentage of women in the 15-49 age group was higher in rural areas than in urban and, respectively, amounted to $25.1 \%$ vs. $16.2 \%$. The percentage of women aged 70 and above was $21.6 \%$ in urban and $17.6 \%$ in the rural female population.

Table 7 presents breast cancer stage distribution between urban and rural areas. The non-significantly higher proportion of the localised stage was documented in urban than in the rural female population, and amounted to $51.0 \%$ and $43.9 \%$, respectively. Regional disease stage occurred in $36.5 \%$ of women living in urban areas and in $40.6 \%$ of rural women. Advanced stage breast cancer was diagnosed in $7.4 \%$ of urban and $9.1 \%$ of rural residents $(\mathrm{p}=0.34)$.

\section{DISCUSSION}

In Poland, geographical differences in health status of the population have been observed for years $[11,12,13,14]$. Breast cancer incidence in women is one of the manifestations of regional Polish population health condition diversification. In comparison with the inhabitants of the western regions, women living in the north-eastern part of the country are characterised by a lower risk of developing breast cancer. However, since the beginning of the 1990s, the regional differences in the risk of breast cancer in Poland have been reduced $[15,16,17,18]$.

Studies of cancer incidence and mortality according to place of residence (urban/rural) have been conducted in Poland since the beginning of the 1960s, and concerned, in particular, Warsaw and Krakow, as well as rural areas adjacent to these cities. From the beginning of this study in 2002, a higher incidence of breast cancer was observed in the urban population. In 1962-1965, the urban/rural ratio was 2.1. In $1970-1974$, the urban-rural difference in incidence decreased to 1.7. In the 1980 s, there was a further inequality reduction in the incidence between residents of urban and rural areas; RR indicator - $1.5[19,20]$.

Study of breast cancer incidence in 1980-1984 in the urban and rural population of the north-eastern region, encompassing the former Provinces of Białystok, Łomża and Suwałki, showed a higher incidence of breast cancer among women living in urban areas [21].
The Świętokrzyskie Province is a region in which the incidence rates were lower than in the rest of Poland. The average annual standardized incidence rate in the Świętokrzyskie Province in 2002-2013 amounted to 42.1/105, and in Poland $-47.0 / 10^{5}$.

The higher breast cancer incidence in urban areas could be due to higher exposure to carcinogens in urban areas [22], may also be due to changes in lifestyle factors, including sedentary lifestyle [23]. Higher socio-economic status is associated with a higher incidence of breast cancer [24]. According to data from the Central Statistical Office in Poland, higher levels of education and higher incomes are observed in women living in urban areas [25]. The incidence of breast cancer is also increasing along with changing reproductive patterns related to urbanization and socio-economic development [26]. In 2016, in the Świętokrzyskie Province the total fertility rate was lower in urban areas than in rural areas and amounted to 1.12 and 1.26, respectively [27]. An increasing number of live births is likely to be responsible for a decrease in breast cancer risk [28].

The results of this study indicate urban-rural inequalities in the burden of breast cancer. In 2002-2013, breast cancer incidence in the Świętokrzyskie Province was higher in urban women than in rural women. The largest differences in the incidence of breast cancer between urban and rural residents in the Świętokrzyskie Province were observed in women aged 70 and over; RR index -1.82 . The smallest urban-rural differences in breast cancer incidence were in the age group 15-69 years, where the average RR value was 1.40 . Diversification of socio-economic status and environmental factors may have greatest impact on the increased risk of developing breast cancer in younger women.

The results of the presented study revealed that in 2013, compared to 2002, an inequalities reduction in the incidence of urban-rural breast cancer was observed, according to the $\mathrm{RR}$, which is favourable from the health policy point of view aimed at eliminating health inequalities.

Study by Krzyżak et al. in the Podlaskie Province in Poland in 2001-2002, similar to the Świętokrzyskie Province, showed a higher incidence of breast cancer in urban than in rural areas; average RR value - 1.4 [29].

Significant urban-rural differences in breast cancer incidence in the central region of Italy has been shown by Minelli et al. Until 2002, no population screening had been carried out in the region, which could also have contributed to the lower incidence in rural areas [30].

According to the forecast for 2010-2025, in Poland the largest increase in breast cancer incidence will be observed in the age group recommended for screening [19]. The Population Programme for Early Breast Cancer Detection in Poland began in 2006. The results of this study indicated the highest level of incidence in the age group of women covered by a screening programme in the Swiętokrzyskie Province. Improvement of breast cancer detection might have an impact on the increase in breast cancer incidence [31]. Some histologically-confirmed small cancers detected in the screening might not become clinically apparent during the patient's lifetime [32]. False-positive recall is indicated as the most prominent downside effect of population breast screening [33].

Improved health care access and density of primary care physicians in the urban population may explain the urbanrural inequalities in breast cancer incidence [34]. 
In the Świętokrzyskie Province an increase in the incidence of breast cancer was observed in both groups of patients: urban and rural women. However, the analysis of trends showed that the pace and direction of change were developing negatively among the inhabitants of rural areas. The observed increase in the number of breast cancer cases may result from the improvement in breast cancer detection, and growing awareness about the disease.

The results of the current study indicate rural disadvantage in breast cancer stage distribution, taking into account place of residence. Analysis of urban-rural differences in disease stage distribution revealed a non-significantly higher proportion of cases with localised stage in urban than in rural areas, amounting to $51.0 \%$ and $43.9 \%$, respectively. The proportion of regional and advanced breast cancer stage was highest among patients living in rural areas. Urban-rural inequalities in breast cancer stage distribution were also observed in the Podlaskie Province in Poland. The percentage of patients with localised breast cancer stage in the Podlaskie Province was lower than in the Świętokrzyskie Province, and amounted to $34.9 \%$ among urban, and $29.1 \%$ in rural patients.

Secondary prevention in combating breast cancer plays an important role. The moment of diagnosis of the disease may affect the patient's cure and prognosis, which suggests the need to make efforts focused on programmes for early diagnosis and detection of cancer. The unfavourable stage distribution of breast cancer in the rural population may indicate insufficient knowledge about the importance of early diagnosis, as well as may indicate worse access to health care for rural residents, including programmes aimed at early detection of breast cancer.

Research by Jokiel et al. showed that rural women in Poland were characterised by unfavourable health behaviours concerning breast cancer prevention [35]. Studies in Croatia showed that health promotion and health education were insufficient in rural areas [36].

As shown earlier, the rural population is characterised by a lower socio-economic status. According to the study by MacKinnon et al., breast cancer cases were diagnosed later among residents of areas with high poverty levels [37]. Interventions aimed at reducing health inequalities should focus on health promotion and raising health awareness, paying special attention to early cancer detection programmes [38]. Interventions to enhance breast cancer detection and early treatment of patients with lower socio-economic status may contribute to reducing health inequalities [39].

Research by McLafferty et al. in Chicago, USA, revealed that in the analysed time periods (1988-1992; 1998-2002), the risk of late-stage breast cancer was highest among patients living in the most urbanized areas [40]. However, systematic review and meta-analysis of 21 studies concluded that patients living in rural areas were more likely to be diagnosed with late-stage breast cancer [41].

\section{CONCLUSIONS}

The results of this study revealed noticeable inequalities in the burden of breast cancer in the female population of the Świętokrzyskie Province, considering place of residence. Incidence rates were higher in urban than in rural areas. However, the analysis of trends showed that the pace and direction of change were developing negatively among the rural population. In 2013, compared to 2002, inequalities reduction in urban-rural breast cancer incidence was observed according to the RR, which is favourable from the health policy point of view aimed at eliminating health inequalities. The results indicated the existence of urbanrural disparities in the breast cancer stage distribution. The unfavourable breast cancer stage distribution in rural population may indicate insufficient knowledge about the importance of early diagnosis, as well as may indicate worse access to health care for rural residents, including programmes aimed at early detection of breast cancer. The urban-rural differentiation in breast cancer incidence and disease stage distribution investigated in this research should be considered as the appearances of health inequalities in the Świętokrzyskie Province. Existing health inequalities indicate the need to intensify activities in rural areas, and should be the starting point for making key decisions on combating breast cancer.

\section{Acknowledgments}

This research was financed under Project ERA-NET TRANSCAN 1/2015, financed by the National Centre for Research and Development in Warsaw, pursuant to Decision No. DZP/TRANSCAN III/168/2015.

\section{Conflict of interest}

The authors declare no conflict of interest.

\section{REFERENCES}

1. Torre LA, Bray F, Siegel RL, Ferlay J, Lortet-Tieulent J, Jemal A. Global Cancer Statistics, 2012. Ca Cancer J Clin. 2015; 65: 87-1083.

2. Micheli A, Capocaccia R, Martinez C, et al. Cancer control in Europe: a proposed set of European cancer health indicators. Eur J Public Health. 2003; 13, suppl. 3: 116-118.

3. Regulation of the Council of Ministers of 4 August 2016 on the National Health Program for 2016-2020. Dz. U. z 2016 r. poz. 1492.

4. Ahmad O, Boschi-Pinto C, Lopez A, Murray C, Lozano R, Inoue M. GPE Discussion Paper Series: no31. Age standardization of rates: a new WHO standard. World Health Organization, 2001.

5. Silman AJ, Macfarlane GJ. Epidemiological studies: A practical guide. Second edition: Cambridge University Press, 2002.

6. International Classification of Diseases for Oncology, Third Edition, First Revision. Geneva: World Health Organization, 2013.

7. European Network Of Cancer Registries (ENCR): ENCR Recommendations, Condensed TNM for Coding the Extent of Disease, April 2002.

8. National Cancer Institute. Joinpoint Regression Program. version 4.2.0.2, June 23 2015, (Available at http://surveillance.cancer.gov/ joinpoint/).

9. Breen N, Scott S, Percy-Laurry A, Lewis D, Glasgow R. Health disparities calculator: a methodologically rigorous tool for analyzing inequalities in population health. Am J Public Health 2014; 104(9): 1589-91.

10. National Cancer Institute, Division of Cancer Control and Population Sciences, Surveillance Research Program and Applied Research Program. Health Disparities Calculator, Version 1.2.4 2013.

11. Wojtyniak B, Rabczenko D, Pokarowski P, et al. Atlas of mortality of the Polish population in 1999-2001 and 2008-2010 - online edition; www.atlas.pzh.gov.pl

12. Lipowicz A. Disparities in health status between rural and urban adult males in Lower Silesia, Poland. Anthropol Anz. 2015; 72(1): 13-25

13. Maniecka-Bryła I, Pikala M, Bryła M. Health inequalities among rural and urban inhibitants of Łódż province, Poland. Ann Agric Environ Med. 2012; 19(4): 723-731.

14. Staszewski J.Regional differences in mortality from malignant tumors in Poland in 1970-1974.Gliwice: Instytut Onkologii; 1979.

15. Zatoński W, Tyczyński J. Cancer in Poland. Cancer Detect Prev. 1993; 17(4-5): 459-68.

16. Staszewski J. Regional differences in mortality from malignant tumors in Poland in 1975-1976. Polski Tygodnik Lekarski 1981; 36(2): 49-51. 
17. Staszewski J. Regional differences in mortality from malignant tumors in Poland in 1961 and 1970-1971. Nowotwory 1975; 25(2): 187-192.

18. Wojtyniak B, Rabczenko D, Pokarowski P, et al. Atlas of mortality of the Polish population in 1999-2001 and 2008-2010 - online edition; www.atlas.pzh.gov.pl

19. Didkowska J, Wojciechowska U. Breast cancer in Poland and Europe - population and statistics. Nowotwory. J Oncol. 2013; 63(2): 111-118.

20. Koszarowski T, Gadomska H, Warda B, Drożdżewska Z. Research on cancer incidence and mortality in Poland and in selected areas 1962-1965. Polish Medical Publishers, Warsaw; 1968.

21. Korfel A, Korfel Y, Juczewska M, Szachidewicz J, Rybaczuk M. Mammary carcinoma in the urban and rural populations of the northeastern region. Materials of the 6th Scientific Congress of Physicians of the Białystok, Łomża and Suwałki.1986 February 7; Białystok; Poland.

22. Mahdavifar N, Pakzad R, Ghoncheh M, Pakzad I, Moudi A, Salehiniya H. Spatial analysis of breast cancer in India. Asian Pac J Cancer Prev. 2016; 17(S3): 59-64.

23. Mathew A, Kalavathy MC, George PS, Jagathnath Krishna KM and Sebastian P. Urban-Rural Disparities in Female Cancer Incidence and Mortality in Trivandrum, South India. Ann Transl Med Epidemiol. 2017; 4(1): 1011.

24. Lundqvist A, Andersson E, Ahlberg I, Nilbert M, Gerdtham U. Socioeconomic inequalities in breast cancer incidence and mortality in Europe - a systematic review and meta-analysis. Eur J Pub Health. 2016; 26(5): 804-813.

25. Central Statistical Office, Statistical Office In Olsztyn. Rural areas in Poland, Warszawa, Olsztyn, 2011.

26. Fei X, Wu J, Kong Z, Christakos G. Urban-Rural Disparity of Breast Cancer and Socioeconomic Risk Factors in China. PLoS One. 2015; 10(2): e0117572.

27. Central Statistical Office. Statistical yearbook of the Świętokrzyskie Voivodship, Kielce, 2017.

28. Khalis M, Charbotel B, Chajès V, Rinaldi S, Moskal A, Biessy C, et al. Menstrual and reproductive factors and risk of breast cancer: A casecontrol study in the Fez region, Morocco. PLoS ONE. 2018; 13(1): e0191333.

29. Krzyzak M, Maslach D, Juczewska M, Lasota W, Rabczenko D, Marcinkowski J, Szpak A. Differences in breast cancer incidence and stage distribution between urban and rural female population in
Podlaskie Voivodship, Poland in years 2001-2002. Ann Agric Environ Med. 2010; 17(1): 159-62.

30. Minelli L, Stracci F, Cassetti T, et al. Urban-rural differences in gynaecological cancer occurrence in a Central Region of Italy: 19781982 and 1998-2002. Eur J Gynaecol Oncol. 2007: 28(6): 468-72.

31. Harding C, Pompei F, Burmistrov D, Welch HG, Abebe R, Wilson R. Breast Cancer Screening, Incidence, and Mortality Across US Counties. JAMA Intern Med. 2015; 175(9): 1483-1489.

32. Morris E, Feig SA, Drexler M, Lehman C. Implications of Overdiagnosis: Impact on Screening Mammography Practices. Popul Health Manag. 2015; 18 Suppl 1(Suppl 1): S3-11.

33. Houssami N. Overdiagnosis of breast cancer in population screening: does it make breast screening worthless? Cancer Biol Med. 2017; 14(1):1-8.

34. Moss JL, Liu B, Feuer EJ. Urban/Rural Differences in Breast and Cervical Cancer Incidence: The Mediating Roles of Socioeconomic Status and Provider Density. Womens Health Issues. 2017; 27(6): 683-691.

35. Jokiel M, Bielska-Lasota M, Kraszewska E. Breast cancer prevention - awareness and health beheviour changes of women in 1998-2002. Przegl Epidemiol. 2003; 3, 521-530.

36. Stamenić V, Strnad M. Urban-rural differences in a population-based breast cancer screening program in Croatia. Croat Med J. 2011; 52(1): 76-86.

37. MacKinnon JA, Duncan RC, Huang Y, et al. Detecting an association between socioeconomic status and late stage breast cancer using spatial analysis and area-based measures. Cancer Epidemiol Biomarkers Prev. 2007; 16(4): 756-762.

38. Nikolaidis Ch, Guimarães RM, Constantinidis TC. Rural/urban disparities in cancer mortality: a case - study from northeast Greece. Cad Saude Colet 2012; 20(3): 336-340.

39. Yu XQ. Socioeconomic disparities in breast cancer survival: relation to stage at diagnosis, treatment and race. BMC Cancer. 2009; 9:364.

40. McLafferty S, Wang F, Luo L, Butler J. Rural-urban inequalities in latestage breast cancer: spatial and social dimensions of risk and access. Environ Plann B Plann Des. 2011; 38(4): 726-740.

41. Pruitt SL, Eberth JM, Morris ES, Grinsfelder DB, Cuate EL. RuralUrban Differences in Late-Stage Breast Cancer: Do Associations Differ by Rural-Urban Classification System? Tex Public Health J. 2015; 67(2): $19-27$. 